\title{
The evolving role of EU Regional Policy: Implications for Australia?
}

\author{
Bruce Wilson \\ Bruce.wilson@rmit.edu.au
}

\begin{abstract}
In 2013, ANZJES published an article on the significance of European Union (EU) Regional Policy in the process of European integration and its implications for Asia. Over the past decade, EU Regional Policy has evolved considerably. It is still centred on facilitating European integration, but also assumes a much more central role in focusing attention on harnessing resources, intellectual and economic, in order to address major societal missions. Regional Policy, or Cohesion, funds constitute approximately one third of the total European Commission budget and are, therefore, not only an important resource for integration, but also for addressing the wider priorities around the European Green Deal, and indeed, the planet. This is evident in the proposed Multiannual Financial Framework agreed by the European Council for 2021-27, in which Cohesion funding is seen to be a crucial resource for economic and social recovery from the COVID-19 crisis. This article reviews the evolution of this thinking in the last decade and considers its growing international significance. Whilst not necessarily imagined in 2010, when the EU established its European External Action Service (EEAS), a focus on regions and their innovation systems has enabled the EU to strengthen its global influence significantly.
\end{abstract}

Keywords: Regional Policy; Smart Specialisation; Mission-oriented innovation; EU science diplomacy

\section{Introduction}

EU Regional Policy has been an essential part of European integration for more than 30 years. As it has evolved over the past decade, it has assumed a more central role in focusing attention on how regions can be innovative in contributing to action on major societal missions. Regional Policy funds are also an important resource for addressing the wider priorities around the European Green Deal, and indeed, the planet. This is evident in the proposed Multiannual Financial Framework agreed by the European Council for 2021-27, in which Cohesion funding is seen to be a crucial resource for economic and social recovery from the Covid-19 crisis. This article reviews the evolution of this thinking in the last decade and considers its growing international significance. Whilst not necessarily imagined in 2010, when the EU established its European External Action Service (EEAS), a focus on regions and their innovation systems has enabled the EU to strengthen its global influence significantly.

\section{Regional Policy and Convergence}


The broadening of the Cohesion agenda is a significant development, given the longstanding emphasis on convergence. In 2013, Wilson commented that:

Regional Policy needs to be seen alongside the Schengen Treaty and the Eurozone as a key means of facilitating the conditions for effective Europeanwide movements of people and goods. Over time, the products and services of poorer regions should be able to compete in the wealthier areas of Europe, the incomes and standard of their populations should improve and their markets ought to offer similar opportunities for consumers as in the wealthier regions $(2013,21)$.

This focus on integration did not emerge naturally. The evolution of Regional Policy from 1985 onwards was a hotly contested process, as the European Commission (EC) sought to exert greater influence over both policy initiatives and the actual expenditure of the Regional Policy funding, also known as the structural funds and as Cohesion Funding. Member States resisted the apparent incursion of the EC into the determination of funding decisions within their borders. Each new negotiation of the multiannual financial agreements leading up to 2007-13 saw increasingly intense discussion over the shape and direction of the funding envelope for each Member State receiving Regional Policy funding, as the Commission sought to consolidate more and more specific guidelines.

As Commission influence over implementation strengthened, other political decisions shaping the implementation of Regional Policy were apparent in the strengthening of the links between Regional Policy and other areas of EC expenditure. In the lead-up to 2007, there was broad emphasis on projects to promote environmental sustainability, and more explicit connections with rural development and maritime and fisheries programs (European Commission, 2010).

Overall, the approach to Regional Policy seems to have been vindicated as greater convergence across EU territories was achieved, notwithstanding some disruption in the patterns of disparities since the Global Financial Crisis in 2009, and more general complexity in incomes across time and space (Monfort, 2020). The crisis had different effects across European regions, some even continuing to grow rapidly while others slowed rapidly. While this correlation cannot be attributed directly to Cohesion spending, it has clearly contributed to the EU being seen as a 'convergence machine' up until the financial crisis (Monfort, 2020, 2).

However, even while Regional Policy took on greater prominence within the EU, debate about the intent and the effectiveness of Regional Policy and its funds continued, not least because of concern about corruption and misallocation of priorities. Questions were asked also about the complementarity of the spread of the Cohesion Funds with Member State programs with respect to labour market, welfare, rural and transport initiatives, for example (Polverari \& Michie, 2011). As Wilson noted:

... there is scarcely an aspect of Regional Policy which has not been subject to critical review, from independent researchers and from key stakeholders in the various institutions of the European Union itself. Successive processes within the Commission (such as the Barca Report in 2009) have continually recognised these critiques and attempted to redefine the policy framework in a 
manner that clarified its rationale, and improved its implementation. More recently, there has been active collaboration with the OECD in the effort to understand the dynamics of institutional investment in regional development, and how this might be accomplished most effectively (Wilson, 2013, 23).

The OECD role was influential. In 2009, the OECD published Regions Matter, a comprehensive review of regional development policies across the 36 member nations. The report argued very strongly for a clear focus on growth-oriented regional policies that were centred on innovation. They called for strategy which developed endogenous assets rather than distributing grants or allocating infrastructure funds as separate initiatives.

The key appears to be how assets are used, how different actors interact and how synergies are exploited. Evidence of this is provided by analysis of the factors that generate growth: for example, infrastructure investment is effective when combined with other forms of investment, notably in education and skills. For innovation, it is not only the number of researchers or the level of R\&D investment that count, but how the innovation system as a whole functions. This leads to very different kinds of public policy considerations ... public policy needs to embrace reform and continue a transition away from marketdistorting subsidies to policies that unlock the potential of regions and that support long-term economic, social and environmental objectives (OECD, 2009, 3).

The two dynamics, one focused on strengthening the place-based focus of Regional Policy, and the other addressing the opportunity to support innovation-driven growth, came together in 2010-2013 to form the approach now known as Smart Specialisation. This led to fundamental reforms to Regional Policy and to the disbursement of the Cohesion Funds which were enshrined in policy for the 2014-2020 multiannual financial period.

This process started a new phase of thinking about much closer integration of Regional Policy with other major priorities for the European Union, and with other investment initiatives. This article reviews the evolution of this thinking in the last decade and considers its growing international significance. Whilst not necessarily imagined in 2010, when the EU established its European External Action Service (EEAS), a focus on regions and their innovation systems has also enabled the EU to strengthen its global influence significantly.

\section{The Rise of Smart Specialisation}

As a profound restructuring of the nature and direction of Regional Policy, the rise of Smart Specialisation has been well documented by the OECD (2013), by the European Commission (2012) itself, by Foray (2015), and by many others. Wilson (2016) has provided a review of the potential importance of Smart Specialisation for regions beyond Europe.

At the heart of the new approach was the recognition that knowledge was becoming the central resource for the new economy. While Europe had very significant science and knowledge resources, it had lagged behind the United States and Japan in relation to successful commercialisation of their science outputs. This insight, together with 
OECD research which demonstrated that regions' economic performance varied within as well as across national boundaries (see OECD 2009), led the EC's DG Regio to propose a very different approach to determining priorities for dispersal of Regional Policy funds.

The process proposed by the European Commission drew heavily on European research on regional innovation systems, where close collaboration between business, researchers and government agencies had enabled innovation to flourish and thus enhance regional economic (and social) performance. Hence, rather than decisions being made by National Management Committees, Smart Specialisation brought a much stronger focus on participative decision-making in regions themselves. In the new arrangements, regional authorities were required to:

a) conduct a detailed analysis of their regional context, with particular emphasis on identifying key assets, particularly knowledge assets, from which the region could build competitive advantage;

b) sub-national regions then had to agree on appropriate governance arrangements that would allow a voice for key regional stakeholders. Increasingly, this was understood to include the quadruple helix: business, researchers/educators, government and civil society;

c) key stakeholders needed to agree on a vision for the region, before engaging in what was referred to as the Entrepreneurial Discovery Process (EDP). The EDP has been a critical part of the process for developing priorities, bringing together cross-sectoral perspectives focused on the key knowledge assets and their competitive potential, specifically in relation to the evolving character of global value chains;

d) the EDP processes contributed to the development of Roadmaps with appropriate monitoring and evaluation milestones (European Commission, 2012).

The new centrality of Smart Specialisation was demonstrated by the requirement that each region seeking a share of the regional funds had firstly to adopt a Smart Specialisation Strategy (S3). This ex ante conditionality represented an imperative that enabled many regional stakeholders to be engaged much more than had been the case previously. It prompted considerable learning about a fundamentally different process to developing strategies. This applied also to the implementation of the resulting strategic Roadmaps. Most typically, this involved calls for tender in which appropriate cross-sectoral consortia could win funds to implement the innovation opportunities identified in the Roadmaps.

In summary,

... this is an engaged planning process which brings together 'entrepreneurially minded public sector officials with business, academic and community participants to examine local (knowledge) assets and identify new opportunities in restructured value chains. 'Entrepreneurial discovery' enables knowledgebased assets (not industries) to be the central focus of analysis (see Foray, 2015). The public sector plays 'a catalytic role' in driving innovation and growth in a particular place (see Mazzucato 2013). The outcome is a vision of the region's future, and the critical areas for support and investment, that will enable the vision to be realised (Wilson, 2016, 3). 
This was a dramatic change of approach. Nevertheless, important support was implemented to assist regions in new ways of thinking. Even prior to 2014, and the start of the new financial period, DG Regio was promoting those regions which already had a strong innovation focus. Ten regions were identified as part of the 'Vanguard Initiative', and the Commission established the Smart Specialisation Platform as a resource to assist regions. The Platform offered resource materials, specific advisory services, a peer review program which brought regions facing similar issues together to share experiences and problem-solving. It published an extensive series of working papers and reports which both illuminated specific issues or relationships, or shared emerging practice amongst all regions. Thematic Groups were established to facilitate ongoing sharing of experience particularly where regions shared a focus, on agri-food or energy, for example (see https://s3platform.jrc.ec.europa.eu/thematic-platforms).

By 2016, more than 120 regions had developed strategies and were developing calls for implementation of specific initiatives. However, around this time, it was becoming apparent also that those regions who were eligible for the largest injection of Cohesion Funds were also those least able to engage with the new and demanding processes which emphasised hard choices about innovation opportunities. This was becoming apparent particularly in those regions which were continuing to struggle to escape the worst consequences of the 2008-09 global financial crisis.

Marques and Morgan (2018) suggested that this was because those lagging regions struggled to mobilise the institutional capacity necessary to maximise the benefits of the smart specialisation process. They identified a number of 'heroic assumptions' which had underpinned the design of smart specialisation. These included:

a) regional elites are committed universally to innovation;

b) the public sector in any region has the expertise necessary to implement a complex new regional innovation system process;

c) policy makers recognise that innovation is an open, problem-solving process, rather than linear, driven by science;

d) university, business and government agencies already form a coalition that can work together on innovation opportunities; and

e) regions are capable of managing intergovernmental relations with national, supranational and local authorities effectively (Marques \& Morgan, 2018, section 2).

Notwithstanding these difficulties in less dynamic regions, the new policy engendered quite different ways of working that were much more inclusive. Through the support of the Joint Research Centre (JRC) and the Smart Specialisation Platform, extensive support was provided also for interregional collaboration, and for linking together the innovation opportunities emerging in Smart Specialisation Strategies with initiatives promoted by other DGs. This has happened partly through the S3 Platform's Thematic Platforms which have links with DGs REGIO, AGRI, ENER, GROW and RTD. Another important aspect of this new innovation - orientation in Regional Policy was an effort to build stronger connections with other parts of the EU's research and innovation arrangements, including Horizon 2020 and the Knowledge and Innovation Communities set up by the European Institute of Technology. 
The JRC, with the S3 Platform, has also initiated a group of projects under the banner of STRIVE, to work in practical ways with national and regional stakeholders on the implementation of the regional innovation processes that have been promoted by smart specialisation. These projects have brought together the quadruple helix stakeholders to focus in some cases, on promoting excellence, on the challenges of lagging regions, and on the specific role of higher education institutions in supporting RIS3 initiatives (see Özbolat et al., 2019, 16).

Yet it has also been very complex and demanding. The European Commission itself released a report which reflected on the challenge of generating effective collaboration. In commenting in particular on efforts to link the more entrepreneurial approach of S3 with other EU initiatives designed to promote excellent science, it appears that collaboration did not come easily.

Collaborative activities aiming at the creation of knowledge and achieving innovation require a shift from silo thinking to joint perspective and common understanding, as well as shared vision between main actors. They are also connected to the establishment of mutual trust and an ownership of the activities accepted by each component of the collaboration (Özbolat et al., 2019, 40).

Evaluation has been an important component of Smart Specialisation processes from the outset, but the principal concern since 2014 has been on supporting learning, particularly about governance, about the entrepreneurial discovery process, and implementation of roadmaps. The scale of change, both in regions themselves, and in the EU's implementation of Regional Policy has been enormous, prompting reshaping of relationships, accountability, and a quite different focus on evidence. The emphasis on identifying regional assets and related innovation opportunities has been confronting for many regions, especially those which have struggled with building collaboration amongst the quadruple helix stakeholders and developing the capability necessary to support each of the S3 stages. However, after five years, there is a strong commitment across Europe to the new ways of working, and to understanding the links between endogenous innovation and broader questions of regional social and environmental development (for example, Guzzo \& Perionez-Forte, 2019).

\section{The International Dimension}

Quite apart from the impact of $\mathrm{S}_{3}$ within the EU, there has been growing interest in other parts of the world. The EU has been able to engage with many countries in strategic locations, each of which is interested to explore whether or not the $\mathrm{S}_{3}$ approach can assist them to re-gear their economies and social outcomes. In the first place, these international forays were guided by EU Enlargement and Neighbourhood policies. The first group of countries includes Serbia, Montenegro, North Macedonia, Kosovo, Albania and Turkey, while the second involves Moldova, Ukraine, Georgia and Tunisia (Özbolat et al., 2019).

Most prominent in this regard has been Serbia. The S3 Platform has worked closely with Serbian authorities to do a detailed context analysis and then supported a Discovery process to identify innovation opportunities, especially those related to science and technological innovation (see Bole et al., 2019). By 2018, there was sufficient analysis to propose an outline of the potential priorities for a science and 
technology Roadmap in Serbia (see Matusiak, 2020). In the last couple of years, the Serbian government has extended their collaboration with the S3 Platform to explore the relevance of the S3 methodology in identifying science, technology and innovation (STI) priorities in relation to addressing the United Nations' Sustainable Development Goals (SDGs). This has become a very important example of the potential to link placebased innovation systems with larger mission-oriented innovation policy (see Matusiak, 2020).

Beyond its neighbours, there has been considerable interest in smart specialisation from national governments, regional authorities and regional researchers in Argentina, Australia, Brazil, Canada, Chile, China, Colombia, Mexico, Peru, South Africa, Thailand and Norway. Indeed, representatives from 30 countries attended the first global workshop on Smart Specialisation in September 2018. Contributions to this event demonstrated the adaptability of the core principles of smart specialisation in a wide variety of settings, some at national level, while others had been trialled in sub-national regions.

Apart from direct benefits in developing regional innovation systems, the workshop revealed the breadth of international interest in EU regional innovation policy, and the potential for a new domain of global influence for the EU.

Through Smart Specialisation worldwide, the EU can be a frontrunner in the promotion of place-based innovation policies across the globe. In a context where a number of countries and regions have already expressed an interest for the Smart Specialisation concept elaborated in the EU, going further towards Smart Specialisation worldwide could allow anchoring Smart Specialisation as a distinctive global EU influence for territorial development policies driven by innovation all over the world (Gómez Prieto et al., 2019, 10).

The international interest offered learning opportunities for EU institutions and regions, but also a foundation for other forms of science diplomacy and engagement, thus elevating the place of research in EU foreign policy. While other EU initiatives, such as Horizon 2020 (and soon to be Horizon Europe) are 'open to the world' and encourage international participation, Smart Specialisation offers a distinctive approach with its strong focus on bridging policy silos, and encouraging the development of innovation eco-systems which are typically place-based and crosssectoral.

There is further scope to anchor Smart Specialisation as a distinctive EU touch for territorial development policies led by innovation across the world. On 12 September 2018, in his annual State of the Union speech..., the President of the Commission Jean-Claude Juncker highlighted that it is time for the EU to be a more active global player on the world scene. Undoubtedly, Smart Specialisation has strong potential in this endeavour. As an innovative, placebased approach to innovation, Smart Specialisation comes from the territories, and for the territories. This makes it fully adaptable to any national or regional context, and able to foster economic transformation in all parts of the world (Gómez Prieto et al., 2019, 21).

Another important outcome of the international interest in Smart Specialisation has been the potential role that it can play in the implementation of the United Nations' 
2030 Agenda for global transformation, with its 17 Sustainable Development Goals (SDGs). This draws attention to a wider debate in Europe about the importance of mission-oriented innovation, and possible connections with Smart Specialisation policy.

\section{The Rise of Mission-Orientated Innovation}

Since Smart Specialisation was introduced as a formal EU initiative in 2014, the United Nations has adopted two significant decisions with respect to global challenges. The first, in September 2015, was the commitment to 'Transforming our World', a program to address the Sustainable Development Goals. This new commitment was to replace the Millennium Development Goals (MDGs), but unlike the MDGs, the new ambitions were to apply to all nations. The new global agenda was endorsed by 193 nations and included an extensive suite of targets and indicators to measure progress.

In November 2015, the UN's Framework Convention on Climate Change met in Paris and adopted legally binding commitments on action to contain global warming to less than 1.5 degrees by 2030. The EU had campaigned strongly for this outcome, and from 2015 onwards, reframed the EU's internal planning and management arrangements so that each Directorate General in the European Commission was explicit about how its work would address the ambitions of relevant SDGs.

This approach amplified a debate which had been underway for a decade about research and innovation policy. Since the mid-2000s, there had been calls for EU funding to be more focused on investment that addressed Grand or Societal Challenges. This became part of the framework for Horizon 2020, the eighth Framework program for 2014-2020, but did not achieve the focus or coordination necessary for transformative impact on European economic and social circumstances (Georghiou et al., 2018).

Hence, in 2017, the European Commissioner for Research and Innovation, Carlos Moedas, asked the Research, Innovation and Science Expert high-level group (RISE) to provide advice on mission-oriented research and innovation policy. At the same time, Mariana Mazzucato was commissioned to produce advice on mission-oriented research and innovation. Mazzucato took the view that missions had to be bold, involving cross-sectoral, interdisciplinary research that engaged multiple actors. They should engage public imagination and offer real progress on complex problems, as well as stimulating European competitiveness.

Missions should be broad enough to engage the public and attract cross-sectoral investment; and remain focussed enough to involve industry and achieve measurable success. By setting the direction for a solution, missions do not specify how to achieve success. Rather, they stimulate the development of a range of different solutions to achieve the objective. As such, a mission can make a significant and concrete contribution to meeting an SDG or Societal Challenge (Mazzucato, 2018, 11).

The RISE group distinguished 'challenges' which involve ambitious but definable and technically feasible achievements (space travel, or a successful vaccination) from 'missions' for which outcomes are less tangible, and problems are 'wicked', involving social and political interests and decision-making. Identifying missions requires 
public engagement and support, preferably achieved through a participatory process (Georghiou et al., 2018).

As indicated by Mazzucato, the UN Global Agenda stands as an important objective of mission-oriented innovation policy. The European Commission's Joint Research Centre (JRC) has taken an important lead in focusing its research agendas on the SDGs, making explicit links with Smart Specialisation. This connection had been suggested in the International Workshop in 2018, as some participants in that workshop (particularly Serbia) were already adapting their Smart Specialisation processes to mobilise action on the achievement of the SDGs in the Serbian context (Matusiak, 2020).

Five aspects of the ways in which Smart Specialisation would be a possible tool for the achievement of the Sustainable Development Goals (SDGs) were identified:

- Place-based approaches can help to localise the SDGs by mobilising local governance and policies that are close to citizens;

- Innovation for sustainable solutions is an element that can act as a spark in the mobilisation of policy action for the achievement of SDGs at the local level;

- The identification of priorities for policy intervention constitutes a way to ensure critical mass;

- The inclusive approach of Smart Specialisation allows the activation of communities anchored in territories, which generates policy options and leads to greater ownership;

- Evidence is available to back up policy decisions, activate communities and guarantee solid monitoring and evaluation processes in order to feed back into the policy process again (Gómez Prieto et al., 2019, 18-19).

This was elevated to being an international project in its own right in 2019, when the JRC partnered with the UN's Inter-Agency Task Team on Science, Technology and Innovation (STI) to explore a Global Pilot program in which Smart Specialisation was one of the methodologies used to develop STI Roadmaps to address the SDGs. The first phase of this work culminated in a series of reports from African, European and Australian presenters on projects in which Smart Specialisation processes had contributed directly to achieving specific SDGs, and a contribution as a side event to the UN's High Level Political Forum for the Global Agenda in July, 2020 (see https://s3platform.jrc.ec.europa.eu/-/sti?inheritRedirect=true).

\section{Implications for Australia}

Australia, as a member of the OECD, was part of the deliberations that contributed to the OECD's report, Regions Matter, in 2009. However, by contrast with the developments in the EU during the past decade, there is minimal evidence of any significant influence at national or state level. Examination of the Australian Federal Government's Regions 2030: Unlocking Opportunity, published in 2017, indicates that the expenditure of funds is fragmented, and committed either to infrastructure or 
to grants programs, spread thinly ('vegemite for all'), with poorly defined criteria for selection (Hogan \& Young, 2015).

Each of the states has a distinct framework for regional development, with discrete programs. Typically, states have also invested significant resources in country areas, also mostly through grants and infrastructure programs. Since 2008, Regional Development Australia (RDA), a national program which brings together support from federal, state and local governments, in each of 52 designated regions, has been intended to coordinate intergovernmental programs. Local committees consult, promote programs, share information with all levels of government and in some instances, support regional planning. An independent review of the RDA program in 2016 found that the vision for collaborative intergovernmental engagement with regions was 'never fully realised'. Rather, support over time had declined as political commitment varied with changing governments and competing priorities, and all levels of government had implemented programs in parallel with the RDA structure rather than taking advantage of the linkages which it promised (Smith, 2016).

Taken together, there is no shortage of government resources allocated to country Australia. The question is effectiveness of this spending. Metropolitan and country incomes have diverged markedly, with country Australia largely in recession with the exception of Western Australia and Queensland where mining production has offered a positive outcome. While drought and declining agricultural production primarily account for this, public policy has had little impact (SGS 2019). In Victoria, the picture has been even starker. Despite significant Victorian government investment, the Gross Regional Product (GRP) of non-metropolitan Victoria has declined in six years of the last 16 since 2005-06 and growth of less than 1\% in another four. Furthermore, the gap in GRP per person between Melbourne and country has continued to widen every year since 2002-03 (VAGO, 2019).

In this context, can the EU experience prompt learning for Australia? Is there scope for a significant extension of EU science diplomacy to engage with Australian policy makers? A foundation for this opportunity can be found in the EU-Australia Framework Agreement, initiated by Prime Minister Gillard in 2010, and signed in 2017. Article 53, Employment and Social Affairs, of the Agreement refers to cooperation on 'regional and social cohesion', thus offering the EU and Australia a legal basis for engaging with these issues.

There are three significant implications for Australian policy from the implementation and development of Smart Specialisation over the past decade, and in particular, the last seven years:

a) how to design and implement Regional Policy which engages with the OECD's encouragement for the 'entrepreneurial state' to focus on endogenous (knowledge) assets and innovation-driven growth;

b) how to connect regional innovation capability, that is grounded in local assets, with the challenges and opportunities that come from focusing national innovation policy on missions, national and global, that address wicked societal challenges; and

c) how to connect regional innovation activities with other significant public and private programs that have regional purpose on the one hand, and mission outcomes on the other. 
However, each of these will require a significant reorientation of current Australian policy arrangements for such diplomacy to be productive. This partly reflects not only the fragmented and distributed character of regional policy, but also the narrow commitment to innovation and a relative naivete with respect to multilevel governance. European experience with the interaction between EU, national and city/regional governments has demonstrated a much more sophisticated view of learning about multilevel governance than has yet developed in Australia (see Daniell \& Kay, 2017). The Australian Government has not engaged closely with the issue of focusing Australian research and innovation on mission-oriented innovation: there are nine national priorities set for the national research councils, while the Chief Scientist has been leading a separate initiative to develop a hydrogen 'roadmap'.

Nevertheless, one Australian region, Gippsland, has implemented the Smart Specialisation process from 2017-20. Initiated by the Latrobe Valley Authority (LVA) in response to the closure of the Hazelwood coal mine and power generator, the process has been implemented in conjunction with industry stakeholders from the food and fibre, new energy, visitor economy and health sectors. It has advanced sufficiently to demonstrate considerable learning about the potential value of Smart Specialisation in Australia.

Some of the early learning has highlighted the importance of developing:

a) a culture of collaboration;

b) the role of the tertiary education and research sector in regional innovation systems;

c) an integrated policy framework that sits within a long-term vision;

d) the consistency and coherence of actions that flow from this in terms of industry-led and government supported and facilitated innovation activities, and;

e) a culture of learning (Goedegebuure et al., 2020).

A number of specific initiatives emerged from the project, offering opportunities for new economic and social development, but also developing the collaboration amongst regional stakeholders that is necessary for a regional innovation system to work effectively. Opportunities emerged in the food and fibre, new energy, visitor economy and health sectors, but even more importantly, cross-sectorally. It was important also in demonstrating the legitimacy of public sector authorities in using public investment to invigorate regional collaboration.

Whilst revealing the potential of the Smart Specialisation process in Australia, it also revealed some obstacles. In the first place, the case studies on the EU's Smart Specialisation Platform reflect a strong focus on the importance of data as the basis for contextual analysis and priority setting. Relevant data at the regional level in Australia was difficult to find, and especially with respect to innovation activities. This was surprising, but many parts of the world simply do not have access to the type of data, particularly related to innovation, that is available in Europe. A second major issue was policy alignment. The opportunities with new energy (wind and solar) reflected this in particular, as Federal and state government policies differed significantly.

The Gippsland experience has also illuminated the possibilities for constructive science diplomacy between the EU and Australia on the second and third implications. One of the key activities offered as part of the Gippsland Smart Specialisation process 
was a study tour to the Netherlands, specifically to share insights on innovation in food and fibre and renewable energies. This experience had a profound impact in prompting Gippsland stakeholders both to recognise innovation opportunities in their region, but also to see the importance of their initiatives in the global context of efforts to meet the commitments of the UN Paris Agreement. An ongoing dialogue between the Netherlands and Gippsland was initiated, with strong interest from the Victorian Government and other key research agencies. In addition, representatives of the LVA and the Smart Specialisation project team contributed to the efforts of the EU's Joint Research Centre to build an international community of Smart Specialisation practitioners, and to explore their contribution to implementation of the United Nation's Sustainable Development Goals.

\section{Conclusion}

By any assessment, the reframing of EU Regional Policy and the deployment of the Cohesion Funds has been a remarkable achievement. Not only have there been significant reforms to the program itself, but it has evolved from an internal EU program focused on convergence and integration, to becoming a subject of considerable international interest and experimentation, not least linked with the challenge of contributing to global missions.

The changes to policy design and implementation have been significant. Regional stakeholders themselves achieved significant voice, the focus shifted to innovationdriven growth, and the legitimacy of the entrepreneurial state established. The centrality of the new approach was signalled clearly with the requirement of an ex ante conditionality that regions need to develop a Smart Specialisation Strategy in order to be eligible to receive funds. Underpinning all of this has been a strong emphasis on the importance of learning, and at every point, this priority has been reinforced, as resources to build collaboration across regions have been strengthened.

Australia, on the other hand, has maintained much the same framework as existed a decade previously. While the EU can demonstrate greater convergence, Australia has exposed growing income inequality between its urban and country regions. Opportunities to learn from the EU can be demonstrated with respect to regional policies themselves, and to the connection between regional well-being and more expansive missions to address broader societal challenges.

The EU-Australia Framework Agreement offers an authority for more formal dialogue on these issues. This could be useful not only in relation to Regional Policy itself in Australia but could also highlight opportunities to bring regional innovation initiatives into the wider framework of national science and innovation policy. This would also focus attention more consistently on the intergovernmental framework, federal, state and local, for collaboration on societal challenges such as climate and the SDGs.

\section{References}

Bole, D., Živković, L., and Nedović, V. (2019). Report on the qualitative analysis of preliminary priority areas in the smart specialization process in the Republic of Serbia Smart Specialisation Platform, Sevilla.

Daniell, K. A. and Kay, A. (2017). Multi-Level Governance: Conceptual Challenges and Case Studies from Australia Canberra, ANU Press. 
European Commission (EC) (2010). Fifth Report on Economic, Social and Territorial Cohesion Brussels, November.

European Commission (2012). Guide to Research and Innovation Strategies for Smart Specialisation Sevilla, Smart Specialisation Platform. May.

Foray, D. (2015). Smart Specialisation: Opportunities and Challenges for Regional Innovation Policy London, Routledge.

Georghiou, L., Tataj, D., Celis, J., Giannini, S., Pavalkis, D., Verganti, R. and Renda, A. (2018). Mission-Oriented Research and Innovation Policy: A RISE Perspective Research, Innovation, Science Expert (RISE) high-level group, European Union, Luxembourg.

Goedegebuure, l., Wilson, B., Coenen, L., Schoen, M., Fastenrath, S., Ward, C. and Shortis, E. (2020). Developing and Implementing a Smart Specialisation Approach for Gippsland 2018-2020 Melbourne Sustainable Society Institute (MSSI), Melbourne.

Gómez Prieto, J., Demblans, A. and Palazuelos Martínez, M. (2019). Smart Specialisation in the world, an EU policy approach helping to discover innovation globally: Outcomes, lessons and reflections from the first global workshop on Smart Specialisation Joint Research Centre, European Union, Luxembourg.

Guzzo, F. and Perianez-Forte, I. (2019). Smart Specialisation at work: evidence from the Peer eXchange and Learning workshops JRC Technical Papers, Luxembourg, European Union.

Hogan, A. and Young, M., eds (2015). Regional and Rural Futures London, Routledge,

Marques, P. and Morgan, K. (2018). 'The Heroic Assumptions of Smart Specialisation: A Sympathetic Critique of Regional Innovation Policy' in A. Isaksen, R. Martin and M. Trippl, eds, New Avenues for Regional Innovation Systems - Theoretical Advances, Empirical Cases and Policy Lessons Switzerland, Springer.

Matusiak, M. (2020). STI Roadmaps for Sustainable Development Goals: Potential impact of Smart Specialisation on SDGs Smart Specialisation Platform, Sevilla.

Mazzucato, M. (2013). The Entrepreneurial State: Debunking Public vs. Private Sector Myths London, Anthem Press.

Mazzucato, M. (2018). Mission-Oriented Research \& Innovation in the European Union: A problem-solving approach to fuel innovation-led growth Luxembourg, European Union.

Monfort, P. (2020). Convergence of EU Regions Redux: Recent Trends in Regional Disparities DG Regio Working Paper 02/2020, Luxembourg, European Union.

OECD (2009). Regions Matter Paris.

OECD (2013) Innovation Driven-Growth in Regions: The Role of Smart Specialisation December Paris

Özbolat, N.K., Haegeman, K. and Sereti, K. (2019). European Institute of Innovation and Technology (EIT) Knowledge and Innovation Communities (KICs): Collaboration in a RIS3 Context Joint Research Centre, Luxembourg, European Union.

Polverari l. and Michie, R., (2011). Complementarity or Conflict: the (in)coherence of Cohesion policy European Policy Research Paper, No. 78 Glasgow, European Policies Research Centre, Strathclyde University. 
SGS Economics and Planning (2019). Economic performance of Australia's cities and regions, 2018-19 Canberra.

Smith, W. (2016). Independent Review of the Regional Development Australia Programme: Final Report Department of Infrastructure and Regional Development, Canberra.

VAGO, Victorian Auditor-General's Office (2019). Outcomes of Investing in Regional Victoria: Independent assurance report to Parliament 2018-19: 17 Victorian Government, Melbourne.

Wilson, B. (2013). 'Regional Policy in the EU Mode of Regionalism: Implications for Asian Integration' Australian and New Zealand Journal of European Studies pp Vol. 5 (1) 17-29, May.

Wilson, B. (2016). 'Smart Specialization and Innovation: a View from Beyond Europe' in A. Nikina and J. M. Pique, eds Areas of Innovation International Association of Science Parks. 